\title{
Klasifikasi Tanaman Obat Berdasarkan Ekstraksi Fitur Morfologi Daun Menggunakan Jaringan Syaraf Tiruan
}

\author{
Kana Saputra $\mathbf{S}^{1}$, Mochammad Iswan Perangin-Angin ${ }^{2}$ \\ ${ }^{1}$ Universitas Pembangunan Panca Budi \\ e-mail: kanasaputras@dosen.pancabudi.ac.id \\ ${ }^{2}$ Universitas Pembangunan Panca Budi \\ e-mail: mochammadiswan@gmail.com
}

\begin{abstract}
Abstrak
Indonesia telah lama mengenal dan menggunakan tanaman yang berkhasiat sebagai obat. Dari banyaknya tanaman obat yang ada di dunia, $80 \%$ tanaman obat tumbuh di hutan tropika yang berada di Indonesia. Sekitar 28.000 spesies tanaman tumbuh dan 1.000 spesies diantaranya telah digunakan sebagai tanaman obat. Dengan banyaknya spesies tanaman obat dan tingkat kemiripan yang tinggi dapat menyebabkan kesalahan dalam proses identifikasi jenis tanaman obat. Sehingga dibutuhkan bantuan komputer untuk mengenali jenis tanaman obat tersebut. Tujuan dari penelitian ini adalah untuk mengidentifikasi jenis tanaman obat menggunakan jaringan syaraf tiruan backpropagation berdasarkan ekstraksi fitur morfologi daun. Hasilnya menujukkan bahwa perubahan nilai learning rate mempengaruhi hasil identifikasi jenis tanaman obat berdasarkan fitur morfologi daun. Hasil perhitungan rata-rata nilai recognition rate sebesar $90 \%$ untuk data training dan $75,56 \%$ untuk data testing terjadi saat learning rate 0,01 . Nilai learning rate terbaik untuk identifikasi jenis tanaman obat adalah 0,01 dengan jumlah rata-rata epoch sebesar 11,67 dan MSE sebesar 0,13. Ini menunjukkan bahwa metode ekstraksi fitur morfologi daun dan algoritma jaringan syaraf tiruan backpropagation sangat baik digunakan untuk mengidentifkasi jenis tanaman obat.
\end{abstract}

Kata Kunci: Ekstraksi Fitur, Jaringan Syaraf Tiruan Backpropagation, Morfologi Daun, Tanaman Obat

\section{Abstract}

Indonesia has known and used a nutritious plant as a medicine. most of the medicinal plants in the world that is $80 \%$ of medicinal plants grown in tropical forests in Indonesia. the plant grows about 28,000 species and 1,000 species of which have been used as medicinal plants. Many species of medicinal plants with a high degree of similarity can cause errors in the process of identifying medicinal plants. Because the problem was needed computer assistance to recognize the types of medicinal plants. This research proposed to identify species of medicinal plants using backpropagation artificial neural network based on leaf morphological feature extraction. The results showed that changes in the value of learning rate influence the identification of medicinal plant species based on leaf morphology features. The calculation average of recognition rate is $90 \%$ for training data and $75.56 \%$ for data testing occurs at learning rate 0.01 . The best learning rate for plant species identification is 0.01 with epoch average is 11.67 and MSE is 0.13 . The results of this research concluded that the leaf morphology feature extraction method and backpropagation artificial neural network algorithm are very well used to identify the types of medicinal plants.

Keywords: Backpropagation Artificial Neural Network, Feature Extraction, Leaf Morphology, Medicinal Plant 


\section{Pendahuluan}

Indonesia telah lama mengenal dan menggunakan tanaman yang berkhasiat sebagai obat. Tanaman obat digunakan sebagai salah satu upaya dalam menanggulangi masalah kesehatan. Pengetahuan tentang tanaman obat berdasarkan pada pengalaman dan ketrampilan yang secara turun temurun telah diwariskan dari satu generasi ke generasi berikutnya (Sari, 2006). Hutan jenis tropika yang berada di Indonesia diperkirakan mencapai 143 juta ha. Hutan tropika merupakan tempat tumbuh $80 \%$ dari tanaman obat yang ada di dunia di mana 28.000 spesies tanaman tumbuh dan 1.000 spesies di antaranya telah digunakan sebagai tanaman obat (Pribadi, 2009). Dengan banyaknya spesies tanaman obat dan tingkat kemiripan yang tinggi dapat menyebabkan kesalahan dalam proses identifikasi jenis tanaman obat. Kesalahan identifikasi jenis tanaman obat dapat berakibat fatal bagi yang mengkonsumsi, bahkan dapat mengakibatkan kematian. Sehingga dibutuhkan dibutuhkan bantuan komputer untuk mengenali jenis tanaman obat tersebut.

Ekstraksi fitur citra daun berdasarkan fitur morfologi pernah digunakan sebagai penciri untuk mengidentifikasi jenis penyakit pada tanaman Jabon dengan hasil menunjukkan bahwa fitur morfologi dapat merepresentasikan karakteristik bentuk penyakit daun pada tanaman Jabon (Manik, Herdiyeni, \& Herliyana, 2016). Selain itu fitur morfologi daun juga pernah digunakan untuk identifikasi jenis tanaman menggunakan algoritma klasifikasi k-Nearest Neighbors dengan hasil akurasi sebesar 92\% (Saragih \& Wahyuni, 2018). Berdasarkan penelitian tersebut menunjukkan bahwa fitur morfologi dapat digunakan sebagai penciri dari suatu daun.

Penelitian tentang penerapan metode jaringan syaraf tiruan pernah dilakukan untuk mengklasifikasi kardiotokografi dengan hasil nilai akurasi yang tinggi yaitu sebesar 99,15\% (Ramdhani, Susanti, Adiwisastra, \& Topiq, 2018). Selain itu metode jaringan syaraf tiruan juga pernah diterapkan untuk mengklasifikasi tanah dengan hasil akurasi untuk 2 kelas sebesar $81.89 \%, 3$ kelas sebesar $83.40 \%$, dan 7 kelas sebesar
63.40\% (Mukminin \& Riana, 2017). Dari penelitian tersebut menunjukkan bahwa metode jaringan syaraf tiruan cukup baik dalam melakukan klasifikasi.

Dalam penelitian ini klasifikasi tanaman obat menggunakan algoritma klasifikasi jaringan syaraf tiruan dengan menggunakan dataset citra daun tanaman obat.

\section{Metode Penelitian \\ Pengumpulan Data}

Citra daun dari tanaman obat yang berjumlah 75 dibagi menjadi 60 data training dan 15 data testing. Setiap jenis tanaman obat memiliki data training berjumlah 12 dan data testing berjumlah 3 seperti yang terlihat pada Tabel 1. Latar belakang citra berwarna putih, sehingga tidak akan mempengaruhi hasil ekstraksi fitur karena ekstraksi fitur yang dilakukan berdasarkan fitur morfologi daun bukan dari warna daun.

Tabel 1. Citra Daun Setiap Tanaman Obat

\begin{tabular}{|c|l|c|c|c|}
\hline \multirow{2}{*}{ No } & \multirow{2}{*}{ Tanaman } & \multicolumn{2}{|c|}{ Kelompok Data } & $\begin{array}{c}\text { Bentuk } \\
\text { Daun }\end{array}$ \\
\hline 2 & Binahong & 12 & 3 & \\
\hline 3 & Jambu & 12 & 3 & \\
\hline 4 & $\begin{array}{l}\text { Keji } \\
\text { Beling }\end{array}$ & 12 & 3 & \\
\hline & Sirih & 12 & 3 & \\
\hline 5 & $\begin{array}{l}\text { Som } \\
\text { Jawa }\end{array}$ & 12 & 3 & \\
\hline \multicolumn{2}{|l|}{ Total } & 60 & 15 & 75 \\
\hline
\end{tabular}

\section{Praproses Data}

Setelah data citra daun diperoleh, maka tahapan selanjutnya adalah praproses citra daun. Terdapat 2 tahapan untuk melakukan praproses data citra daun yang diperoleh. Proses pertama adalah pemotongan citra daun (cropping) dan kedua adalah segmentation citra daun. Pemotongan citra dilakukan untuk memperoleh citra daun secara utuh (full) seperti yang terlihat seperti pada Gambar 1 (a). Sedangkan segmentasi citra bertujuan untuk memisahkan antara objek 
(foreground) dengan background. Hasil segmentasi citra adalah berupa citra biner di mana objek (foreground) yang dikehendaki berwarna putih, sedangkan background yang ingin dihilangkan berwarna hitam seperti yang terlihat pada Gambar 1 (b). Segmentasi merupakan proses yang sangat penting dalam pengenalan objek. Metode segmentasi yang digunakan adalah thresholding. Proses ekstraksi fitur dilakukan setelah proses segmentasi selesai dilakukan.

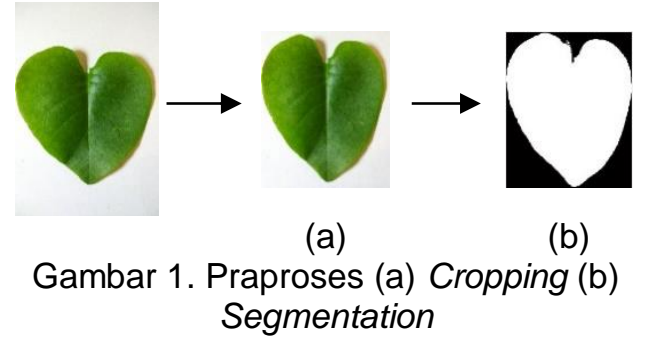

\section{Ekstraksi Fitur}

Untuk ekstraksi fitur morfologi, terdapat beberapa fitur yang dapat dihitung, seperti area dan perimeter. Berdasarkan perhitungan area, perimeter, major axis, dan minor axis, maka fitur morfologi lain juga dapat dihitung. Berikut adalah beberapa formula yang digunakan untuk mengekstraksi fitur morfologi (Manik et al., 2016):

\section{Eccentricity (Ecc)}

Merupakan rasio jarak antar fokus elips dengan panjang sumbu utama (mayor axis) sebuah objek. Eccentricity bernilai antara 0-1. Eccentricity merupakan teknik untuk menggambarkan sebuah objek dengan bentuk elips.

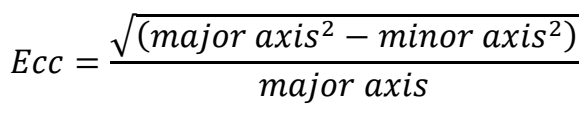

\section{Solidity (Sol)}

Mengukur kepadatan dari sebuah objek, solidity merupakan rasio dari luas wilayah objek ke daerah convex full objek.

$$
\text { Sol }=\frac{\text { area }}{\text { convex_area }}
$$

\section{Rectangularity (Rect)}

Teknik untuk menggambarkan kemiripan bentuk objek dengan bentuk kotak.
Semakin besar nilai rectangularity sebuah objek maka objek tersebut berbentuk kotak.

$$
\text { Rect }=\frac{\text { area }}{\text { major axis } x \text { minor axis }}
$$

\section{Metric (Met)}

Merupakan rasio antara daerah objek dengan daerah lingkaran menggunakan perimeter yang sama. Metric merupakan teknik untuk menggambarkan kekompakkan dari sebuah objek.

$$
\text { Met }=\frac{4 x \pi \times \text { area }}{\text { perimeter }^{2}}
$$

\section{Extent (Ext)}

Proporsi piksel dalam kotak pembatas yang berada di daerah tersebut.

$$
\text { Ext }=\frac{\text { area }}{\text { area of the bounding box }}
$$

\section{Elongation (Elong)}

Mengukur kerampingan sebuah objek. Jika nilai yang diperoleh mendekati 1 maka objek memiliki bentuk yang memanjang.

$$
\text { Elong }=1-\frac{\text { minor axis }}{\text { major axis }}
$$

\section{Pembagian Data}

Pembagian data hasil ekstraksi fitur morfologi daun menggunakan metode $k$-fold cross validation. Jumlah $k$ yang digunakan adalah 3. Mengingat data yang digunakan untuk pelatihan sedikit, pemilihan 3-fold cross validation cukup mampu untuk membuat variasi data, sehingga semua data digunakan, baik untuk data uji maupun data latih. Seluruh data hasil ekstraksi ciri dibagi menjadi 3 subset, yaitu D1, D2, D3. Masingmasing subset memiliki ukuran yang sama. Pada proses pertama D2, D3 menjadi data pelatihan dan D1 menjadi data pengujian, pada proses kedua D1, D3, menjadi data pelatihan dan D2 menjadi data pengujian, dan seterusnya (Manik \& Saragih, 2017).

\section{Jaringan Syaraf Tiruan}

Penelitian ini menggunakan
algoritma jaringan syaraf tiruan backpropagation. Metode ini bekerja melalui proses secara iteratif dengan menggunakan 
sekumpulan contoh data (data training), membandingkan nilai prediksi dari jaringan dengan setiap contoh. Dalam setiap proses, bobot relasi dalam jaringan dimodifikasi untuk meminimalkan nilai Mean Square Error (MSE) antara nilai prediksi dari jaringan dengan nilai sesungguhnya. Modifikasi relasi jarigan syaraf tiruan tersebut dilakukan dengan arah mundur, dari layer keluaran hingga layer pertama dari layer hidden sehingga metode ini disebut sebagai backpropagation (Novita, 2016). Algoritma bacpropagation menggunakan error output untuk mengubah nilai bobotbobotnya dalam arah mundur (backward). Untuk mendapatkan error ini, tahap perambatan maju (forward propagation) harus dikerjakan terlebih dahulu. Pada saat perambatan maju, neuron-neuron diaktifkan dengan menggunakan fungsi aktivasi sigmoid (Dalimunthe, 2016). Penggunaan parameter learning rate untuk setiap kasus berbeda, seperti yang dilakukan pada kasus klasifikasi penyakit diabetes menghasilkan learning rate terbaik sebesar $0,01,0,02$, dan 0,03 (Pandu Cynthia \& Ismanto, 2017). Peneltiian ini menggunakan parameter learning rate sebesar 0,01, 0,02, dan 0,03.

\section{Hasil dan Pembahasan}

\subsection{Ekstraksi Fitur}

Sampel hasil ekstraksi fitur morfologi daun untuk tanaman obat dapat dilihat pada Tabel 2 dan Tabel 3.

Tabel 2. Sampel Ekstraksi Fitur

\begin{tabular}{|l|c|c|c|}
\hline \multirow{2}{*}{ Daun } & \multicolumn{3}{|c|}{ Ekstraksi Fitur } \\
\cline { 2 - 4 } & Ecc & Rect & Sol \\
\hline Binahong & 0,5324 & 0,7546 & 0,9669 \\
\hline Jambu & 0,9157 & 0,7794 & 0,9852 \\
\hline $\begin{array}{l}\text { Keji } \\
\text { Beling }\end{array}$ & 0,7858 & 0,7822 & 0,9757 \\
\hline Sirih & 0,6934 & 0,7668 & 0,9682 \\
\hline $\begin{array}{l}\text { Som } \\
\text { Jawa }\end{array}$ & 0,8595 & 0,7608 & 0,9797 \\
\hline
\end{tabular}

Tabel 3. Lanjutan Sampel Ekstraksi Fitur

\begin{tabular}{|l|c|c|c|}
\hline \multirow{2}{*}{ Daun } & \multicolumn{3}{|c|}{ Ekstraksi Fitur } \\
\cline { 2 - 4 } & Met & Ext & Elong \\
\hline Binahong & 0,5839 & 0,7094 & 0,1535 \\
\hline Jambu & 0,5431 & 0,7435 & 0,598 \\
\hline $\begin{array}{l}\text { Keji } \\
\text { Beling }\end{array}$ & 0,4629 & 0,6938 & 0,3815 \\
\hline
\end{tabular}

\begin{tabular}{|l|c|c|c|} 
Sirih & 0,672 & 0,6652 & 0,2795 \\
\hline $\begin{array}{l}\text { Som } \\
\text { Jawa }\end{array}$ & 0,5691 & 0,6805 & 0,4889 \\
\hline
\end{tabular}

\subsection{Implementasi Jaringan Syaraf Tiruan}

Penelitian ini menggunakan fungsi aktivasi sigmoid biner (logsig) pada hidden layer dan output layer. Sedangkan fungsi pelatihan menggunakan metode LevenbergMarquardt Backpropagation. Jumlah hidden neuron yang digunakan adalah 5, maksimum jumlah epoch adalah 100, dan learning rate sebesar 0,01, 0,02, dan 0,03. Hasil penelitian akan melihat pengaruh perubahan learning rate dan fold terhadap Mean Squared Error (MSE) dan Recognition Rate (\%). Hasil pemrosesan data training dapat dilihat pada Tabel 4.

Tabel 4. Hasil Pemrosesan Data Training

\begin{tabular}{|c|c|c|c|c|}
\hline \multirow{4}{*}{$\begin{array}{c}\text { Fol } \\
d\end{array}$} & $\begin{array}{c}\text { Learni } \\
n g \\
\text { Rate }\end{array}$ & $\begin{array}{c}\text { Jumla } \\
\mathrm{h} \\
\text { Epoc } \\
h\end{array}$ & MSE & $\begin{array}{c}\text { Recogniti } \\
\text { on Rate } \\
(\%)\end{array}$ \\
\hline \multirow{4}{*}{1} & 0,01 & 12 & $\begin{array}{c}0,1279 \\
5\end{array}$ & 78,33 \\
\cline { 2 - 5 } & 0,02 & 13 & $\begin{array}{c}0,6471 \\
4\end{array}$ & 91,67 \\
\cline { 2 - 5 } & 0,03 & 9 & $\begin{array}{c}0,7741 \\
1\end{array}$ & 83,33 \\
\hline \multirow{4}{*}{2} & 0,01 & 11 & $\begin{array}{c}0,2263 \\
5\end{array}$ & 96,67 \\
\cline { 2 - 5 } & 0,02 & 15 & $\begin{array}{c}0,4322 \\
6\end{array}$ & 91,67 \\
\cline { 2 - 5 } & 0,03 & 16 & $\begin{array}{c}0,7870 \\
4\end{array}$ & 93,33 \\
\hline \multirow{4}{*}{3} & 0,01 & 12 & $\begin{array}{c}0,0301 \\
78\end{array}$ & 95 \\
\cline { 2 - 5 } & 0,02 & 10 & $\begin{array}{c}0,5537 \\
7\end{array}$ & 88,33 \\
\cline { 2 - 5 } & 0,03 & 13 & $\begin{array}{c}0,5752 \\
5\end{array}$ & 61,67 \\
\hline
\end{tabular}

Tabel 4 menunjukkan bahwa perubahan nilai learning rate dan jumlah fold mempengaruhi hasil perhitungan recognition rate. Perhitungan recognition rate tertinggi terjadi pada saat fold 2 , learning rate 0,01 , dan MSE 0,22635 yaitu sebesar 96,67\%. Untuk menghindari overfitting, maka dihitung rata-rata dari recognition rate untuk setiap learning rate. Hasil perhitungan rata-rata recognition rate untuk data training dapat dilihat pada Tabel 5. 
Tabel 5. Hasil Perhitungan Rata-rata

\begin{tabular}{|c|c|c|c|}
\hline $\begin{array}{c}\text { Learnin } \\
\text { g Rate }\end{array}$ & $\begin{array}{c}\text { Epoc } \\
h\end{array}$ & $\begin{array}{c}\text { MS } \\
\mathrm{E}\end{array}$ & $\begin{array}{c}\text { Recognition Rate } \\
(\%)\end{array}$ \\
\hline 0,01 & 11,67 & 0,13 & 90,00 \\
\hline 0,02 & 12,67 & 0,54 & 90,56 \\
\hline 0,03 & 12,67 & 0,71 & 79,44 \\
\hline
\end{tabular}

Tabel 5 menunjukkan bahwa ratarata recognition rate tertinggi terjadi pada saat learning rate 0,02 , yaitu sebesar 90,56\%. Akan tetapi berdasarkan pertimbangan rata-rata jumlah epoch dan MSE, maka diambil nilai recognition rate terbaik sebesar $90,00 \%$ pada saat learning rate 0,01 . Untuk membuktikan learning rate 0,01 merupakan yang terbaik, maka dilakukan pengujian menggunakan data testing. Hasil pemrosesan data testing dapat dilihat pada Tabel 6.

Tabel 6. Hasil Pemrosesan Data Testing

\begin{tabular}{|c|c|c|}
\hline Fold & $\begin{array}{c}\text { Learning } \\
\text { Rate }\end{array}$ & $\begin{array}{c}\text { Recognition } \\
\text { Rate (\%) }\end{array}$ \\
\hline \multirow{4}{*}{1} & 0,01 & 80 \\
\cline { 2 - 3 } & 0,02 & 80 \\
\cline { 2 - 3 } & 0,03 & 66,67 \\
\hline \multirow{4}{*}{2} & 0,01 & 66,67 \\
\cline { 2 - 3 } & 0,02 & 73,33 \\
\cline { 2 - 3 } & 0,03 & 73,33 \\
\hline \multirow{4}{*}{3} & 0,01 & 80 \\
\cline { 2 - 3 } & 0,02 & 46,67 \\
\cline { 2 - 3 } & 0,03 & 46,67 \\
\hline
\end{tabular}

Untuk menyesuaikan perhitungan pada saat menggunakan data training, maka dihitung rata-rata dari recognition rate untuk setiap learning rate pada data testing. Hasil perhitungan rata-rata recognition rate untuk data testing dapat dilihat pada Tabel 7.

Tabel 7. Hasil Perhitungan Rata-rata

\begin{tabular}{|c|c|}
\hline $\begin{array}{c}\text { Learning } \\
\text { Rate }\end{array}$ & $\begin{array}{c}\text { Rata-rata Recognition } \\
\text { Rate }(\%)\end{array}$ \\
\hline 0,01 & 75,56 \\
\hline 0,02 & 66,67 \\
\hline 0,03 & 62,22 \\
\hline
\end{tabular}

Berdasarkan perhitungan rata-rata recognition rate pada Tabel 7 terlihat bahwa learning rate 0,01 merupakan yang terbaik dengan hasil perhitungan recognition rate sebesar $75,56 \%$. Ini menunjukkan bahwa learning rate terbaik untuk identifikasi jenis tanaman obat adalah 0,01 dengan jumlah rata-rata epoch sebesar 11,67 dan MSE sebesar 0,13. Rata-rata kesalahan identifikasi terjadi pada daun Binahong, Sirih, dan Som Jawa.

\section{Kesimpulan}

Metode ekstraksi fitur morfologi daun dan algoritma jaringan syaraf tiruan backpropagation sangat baik digunakan untuk mengidentifkasi jenis tanaman obat dengan hasil perhitungan rata-rata nilai recognition rate sebesar $90,00 \%$ untuk data training dan $75,56 \%$ untuk data testing. Perubahan nilai learning rate mempengaruhi hasil identifikasi jenis tanaman obat berdasarkan fitur morfologi daun. Nilai learning rate terbaik untuk identifikasi jenis tanaman obat adalah 0,01 dengan jumlah rata-rata epoch sebesar 11,67 dan MSE sebesar 0,13.

Diharapkan penelitian ini dapat memberikan informasi mengenai parameter yang dapat digunakan pada algoritma jaringan syaraf tiruan backpropagation. Untuk meningkatkan akurasi yang diperoleh dapat mencoba parameter yang berbeda dan menambah jumlah data citra daun tanaman obat.

\section{Referensi}

Dalimunthe, F. H. (2016). Perancangan aplikasi mengidentifikasi penyakit mata dengan menggunakan metode backpropagation. Jurnal Riset Komputer, 3(1), 7-11.

Manik, F. Y., Herdiyeni, Y., \& Herliyana, E. N. (2016). Leaf Morphological Feature Extraction of Digital Image Anthocephalus Cadamba. TELKOMNIKA (Telecommunication Computing Electronics and Control), 14(2), 630. https://doi.org/10.12928/telkomnika.v1 $4 \mathrm{i} 2.2675$

Manik, F. Y., \& Saragih, K. S. (2017). Klasifikasi Belimbing Menggunakan Naïve Bayes Berdasarkan Fitur Warna RGB. IJCCS (Indonesian Journal of Computing and Cybernetics Systems), 11(1),

99. 
https://doi.org/10.22146/ijccs.17838

Mukminin, A., \& Riana, D. (2017). Komparasi Algoritma C4 . 5 , Naïve Bayes Dan Neural Network Untuk Klasifikasi Tanah. Jurnal Informatika, $4(1), 21-31$.

Novita, A. (2016). Prediksi Pergerakan Harga Saham Pada Bank Terbesar Di Indonesia Dengan Metode Backpropagation Neural Network. Jutisi, 05(01), 965-972.

Pandu Cynthia, E., \& Ismanto, E. (2017). Jaringan Syaraf Tiruan Algoritma Backpropagation dalam Memprediksi Ketersediaan Komoditi Pangan Provinsi Riau. Rabit, 2(2), 196-209. Retrieved from http://jurnal.univrab.ac.id/index.php/rab it/article/view/152

Pribadi, E. (2009). Pasokan dan Permintaan Tanaman Obat Indonesia serta Arah Penelitian dan Pengembangannya. Perspektif, 8(1), 52-64. https://doi.org/10.21082/p.v8n1.2009. $\% 25 p$

Ramdhani, Yudi, Sari Susanti, Miftah Farid Adiwisastra, and Salman Topiq. "Penerapan Algoritma Neural Network Untuk Klasifikasi Kardiotokografi." Jurnal Informatika 5, no. 1 (2018): 43-49.

Saragih, K. S., \& Wahyuni, S. (2018). Identifikasi Jenis Tanaman Berdasarkan Ekstraksi Fitur Morfologi Daun Menggunakan K - Nearest Neighbor. Jurnal Teknik Dan Informatika, 5(1), 24-29.

Sari, L. O. R. K. (2006). Pemanfaatan Obat Tradisional Dan Keamanannya. Majalah IImu Kefarmasian, III(1), 1-7. https://doi.org/10.7454/PSR.V3I1.3394 